\title{
MIDAS
}

Museus e estudos interdisciplinares

$6 \mid 2016$

Dossier temático: "Museus, discurso e poder"

\section{O que exatamente torna os museus de hoje tão diferentes, tão atraentes?}

What makes today's museums so different, so appealing?

Ivo André Braz

\section{(2) OpenEdition}

Journals

\section{Edição electrónica}

URL: http://journals.openedition.org/midas/952

DOI: 10.4000/midas.952

ISSN: 2182-9543

\section{Editora:}

Alice Semedo, Paulo Simões Rodrigues, Pedro Casaleiro, Raquel Henriques da Silva, Ana Carvalho

Refêrencia eletrónica

Ivo André Braz, «O que exatamente torna os museus de hoje tão diferentes, tão atraentes? », MIDAS

[Online], 6 | 2016, posto online no dia 04 abril 2016, consultado no dia 24 abril 2019. URL : http:// journals.openedition.org/midas/952; DOI : 10.4000/midas.952

Este documento foi criado de forma automática no dia 24 Abril 2019.

\section{(c) (i) (ㅇ)}

Midas is licensed under a Creative Commons Attribution-NonCommercial-ShareAlike 3.0 International License 


\title{
O que exatamente torna os museus de hoje tão diferentes, tão atraentes?
}

What makes today's museums so different, so appealing?

\author{
Ivo André Braz
}

\section{NOTA DO EDITOR}

Artigo recebido a 31.03.2015

Aprovado para publicação a 04.12.2015

Os anéis de uma serpente são ainda mais complicados que os buracos de uma toupeira.

Deleuze $(2008,226)$

\section{Incipit}

1 Em bom rigor deveríamos começar pelo princípio. Introduzir o tema que vamos tratar. Explicitar os princípios que fundamentam o artigo. Mas é sempre difícil determinar o princípio de um texto. Será que o texto começa em bom rigor ou nestas palavras com que dizemos o quão complicado é determinar o seu início? Ou será que já começou algures? Será que o texto tem o seu princípio no título que, como um bordo superior, encima a mancha da escrita e a enquadra?

2 Ainda que não possamos determinar com rigor o início de um texto podemos partir do princípio de que um título bem-sucedido é um título apropriado. 0 título do presente artigo apropria-se de um outro - Just What is it that Makes Today's Homes so Different, so Appealing? - pertencente a uma conhecida colagem de Richard Hamilton, elaborada em 
1956 como cartaz e parte do catálogo da exposição This is Tomorrow e que constitui uma citação da lógica da cultura mediática e de consumo, com a sua circulação reiterada, delirante e fetichista de estereótipos sexuais, mercantis e tecnológicos (Foster 2004).

O nosso título resulta, assim, de uma apropriação e de um jogo de palavras. Mas, embora se trate de um jogo, ou precisamente por isso, é necessário justificar o título, dar a ver as regras do jogo. $O$ termo estranho ao título original - embora na verdade não exista um original já que o título da colagem foi também ele apropriado por Hamilton (Stonard 2007) - é o museu. Dito de outro modo, é no museu que se dá o jogo. Jogo de palavras que coloca o museu no lugar da casa e transforma o título da colagem no título do nosso artigo.

4 É portanto ao museu que devemos referir os restantes termos - hoje, atratividade, diferença - quando tentamos explicitar o que está aqui em causa. Devemos mesmo supor - para que o jogo funcione com alguma propriedade e a transferência entre o título da colagem e o título do texto tenha lugar - que, de algum modo, há uma relação entre a casa e o museu, que o museu constitui uma imagem apropriada da casa ou que o museu se tornou de tal forma atrativo que nele nos sentimos como se estivéssemos em casa.

5 O que está aqui em jogo é, portanto, a correspondência entre uma lei ou uma gestão do oikos, da casa - uma oikonomia - e uma certa economia do museu. Seria seguramente importante fazer uma arqueologia do processo que conduz da gestão da casa à economia da salvação e desta ao governo dos vivos (Agamben 2011) e, a partir daí, avaliar como as tensões entre o público e o privado, o cuidado e a salvação, a liturgia e o poder, o governo e a conduta, a ordem e a lei se inscrevem no museu.

6 Por agora bastará, porém, que retenhamos a possibilidade - que se joga no título do artigo - da diferença do museu de hoje se situar numa determinada economia e, portanto, numa relação de valor, numa negociação entre um valor absoluto, naturalmente incalculável, e um valor relativo assente numa forma de cálculo ou de enquadramento que simultaneamente separa (delimita as parcelas para possibilitar o cálculo) e acrescenta (valoriza o valor).

7 É certo que podemos sempre acumular os enquadramentos, as molduras enquadramento do museu; enquadramento do museu pelo museu; enquadramento do museu pela cultura em geral; enquadramento do enquadramento enquanto desenquadramento (Oberhardt 2000) -, mas, em qualquer caso, não será possível calcular a diferença do museu de hoje sem ter em conta o modo como o museu se vê, como se dá a ver e como dá a ver o modo como se vê.

Para que o título se mostre apropriado é portanto sobre estas questões - o sentir-se em casa e a atratividade, o cálculo do valor e a economia, a moldura e o enquadramento - que o texto terá que prestar contas ou dar testemunho. 0 que nos leva de volta ao princípio: $o$ que exatamente torna os museus de hoje tão diferentes, tão atraentes?

\section{O museu de hoje}

O que é o museu de hoje? Quando dizemos o museu de hoje, o hoje indica uma diferença, uma atualidade sob a figura da atratividade. Torna-se, assim, necessário que essa atualidade que marca o museu seja, por sua vez, marcada sob a forma de um nome e que esse nome, vindo acrescentar-se ao museu, assinale a diferença entre um hoje e um ontem. Só a partir desse termo adicional, desse suplemento, podemos começar a interrogar o que 
é exatamente o museu de hoje. 0 nosso ponto de partida deverá ser, portanto, o modo como o museu vê a sua diferença - ou como nos diz que vê essa diferença - nomeando o que é e o que deixou de ser.

Dipesh Chakrabarty define o museu nas democracias tardias como performativo por contraposição ao modelo pedagógico característico do século XIX e início do século XX (Chakrabarty 2002, 5-11). Esta oposição resulta de um entendimento diferenciado da capacidade política dos seres humanos. O pedagógico, ao não reconhecer a equivalência entre o humano e o político, assentava num modelo autoritário de transmissão de saber que valorizava a racionalidade analítica - enquanto capacidade de conceptualizar abstrações - e marginalizava outros modos de conhecimento. As alterações socioculturais dos anos 60 do séc. XX - dos fenómenos de massas aos movimentos contraculturais, passando pelas lutas anticoloniais - implicaram uma politização generalizada e conduziram as instituições culturais a um questionamento das suas funções $\mathrm{e}$ metodologias. Assim, de acordo com Chakrabarty: «The museum of today (...) increasingly opens itself up to the embodied and the lived» (Chakrabarty 2002, 9). Ou seja, no museu de hoje a mediação autoritária tende a desaparecer e, através de uma reversão da anterior hierarquia que enaltecia o inteligível sobre o sensível, ocorre uma valorização da capacidade performativa do público enquanto modo de conhecimento incorporado da experiência e da memória.

Se o museu performativo se baseia numa oposição binária relativamente ao pedagógico, o museu construtivista (Hein 2002), proposto por George E. Hein, inscreve-se numa duplicação das dicotomias ao nível da teoria do conhecimento (realista/idealista) e da aprendizagem (ativa/passiva). Estas, por sua vez, desdobram-se em quatro modelos de educação: o didático (que corresponde à tradicional transmissão incremental de um saber que pretende reproduzir a estrutura do objeto perante um sujeito passivo), o de estímuloresposta (centrando no incentivo transmitido e na gratificação da resposta correta), o de descoberta (que reconhece o papel do público na construção do conhecimento, mas requer a sua adequação a uma verdade prévia) e o construtivista (que implica uma produção ativa de conhecimento modelada apenas pela experiência anterior e pelo ambiente de aprendizagem).

o museu construtivista, reconhecendo a capacidade da audiência construir o seu próprio conhecimento, deve complementar essa atividade atendendo às características, capacidades e expetativas diferenciadas dos públicos. Tal implica uma abordagem holística que, do edifício à exposição passando pela interação social, tem em conta todos os componentes, físicos e intelectuais, da experiência museológica. Hein sintetiza este processo no fim do seu livro: «The issue for museums (...) is to determine what meanings visitors do make from their experience, and then to shape the experience to the extent possible by the manipulation of the environment» (Hein 2002, 179).

13 A orientação da planificação museológica para o público está igualmente presente na proposta de um museu cativante por parte de Graham Black, embora neste caso o fio condutor seja o plano de comunicação interpretativa (Black 2005). Black descreve a necessidade do museu abandonar a posição distanciada de guardião autoritário da coleção a fim garantir o envolvimento do público. Com base no princípio de que «through the visitors' stay, museums must be able to respond to expectations in a way that meets the increasingly high demands of audiences accustomed to quality service standards» (Black 2005, 5), o autor irá definir três objetivos: desenvolver uma relação de atração - «the stimulus to visit» (Black 2005, 4) - mediante a imagem projetada para o exterior; 
incentivar uma predisposição para o envolvimento - «the 'right frame of mind' (...) to engage» (Black 2005, 4) - através da qualidade dos serviços e, finalmente, criar as condições para que esse envolvimento se efetive por meio de um plano interpretativo que, englobando todos os aspetos do museu, responda às expectativas e necessidades dos diversos visitantes.

14 A necessidade do museu se afirmar como um espaço de participação direta e ativa é central para Nina Simon (2010). A autora começa por definir o museu participativo como uma resposta ao decréscimo de visitantes nas instituições tradicionais. A necessidade de acolher as expetativas de envolvimento ativo por parte do público implica, para a autora, uma atenção às novas formas de aprendizagem e de entretenimento - associadas sobretudo às tecnologias digitais - adotando os valores destas - «share, create, connect» (Simon 2010, ii) - e adaptando as suas técnicas, ferramentas e design à realidade do museu. A construção de conteúdos pelos utilizadores irá assim basear-se numa forte personalização - «participation begins with me» (Simon 2010, 33) - que deverá valorizar a expressão pessoal e a aquisição produtiva de competências. A dimensão social surgirá, de modo incremental, a partir da individualidade dos participantes - «from me to we» (Simon 2010, 85) - e através de redes de afinidades. Com base nestes pressupostos Simon propõe diferentes formas e modelos de participação - contribuição, colaboração, cocriação, hospedagem - que pretendem adequar as necessidades dos utilizadores aos objetivos das instituições, reforçando o valor estratégico destas.

Eis, portanto, como o museu de hoje nos diz que se vê a si mesmo: um museu participativo, assente em metodologias construtivistas, as quais permitem desenvolver a performatividade do público, tornando-se, por isso, mais cativante para este. Diz-nos igualmente aquilo que o museu atual já não é ou não deve ser. Ou seja, estabelece a sua atratividade a partir de uma diferença - ao nível dos modos de conhecimento, de aprendizagem e de subjetivação (Hooper-Greenhill 2007) - em relação ao museu de ontem.

O museu de ontem, orientando-se para a coleção, afirmava-se como guardião da verdade, ou seja, como detentor de um conhecimento que correspondia integralmente à estrutura do objeto e que, na sua coerência e objetividade, podia ser transmitido. Essa transmissão, linear e incremental, colocava o público numa posição passiva, absorvendo e repetindo a verdade recebida. A posse e a transmissão de conhecimento por parte do museu conferiam a este uma função pedagógica no seu método e normativa nos seus efeitos.

O museu de hoje, ao invés, orienta-se para o público e, tomando em consideração as suas características e necessidades específicas, desenvolve um planeamento global - sem separações entre aprendizagem e entretenimento ou entre razão e sentidos - com que procura complementar a atividade dos visitantes. Cabe, assim, a cada elemento do público assumir uma posição ativa, participativa e construir o seu próprio conhecimento.

Este é o enquadramento teórico que encontramos em diversos textos sobre o museu na contemporaneidade. Torna-se agora necessário apresentar o enquadramento $\mathrm{e}$ problematizar a resposta que ele nos propõe.

\section{Museu a menos: o modelo participativo}

19 Nos textos analisados vimos emergir uma linha divisória que é, sobretudo, uma linha temporal na qual o museu atual se contrapõe ao museu anterior. Ao longo dessa linha, através de cortes profundos e de convivências complexas, surgem situações de oposição, 
de hierarquização e, sempre, de inversão: entre o pedagógico e o participativo ao nível do museu e entre o passivo e o ativo ao nível do público.

Um processo de inversão pode ser caraterizado como uma alteração na ordem dos termos no âmbito de uma oposição binária (Derrida 2001). Aí reside o seu potencial emancipador e a sua limitação enquanto prática teórica. A inversão desnaturaliza o ordenamento anterior - demonstrando que a relação entre os termos não correspondia a uma convivência horizontal, mas a uma hierarquia comandada pelo termo maior - ao mesmo tempo que fortalece o termo previamente menorizado. Contudo, a alteração na ordem dos termos, ao não romper a estrutura, retém a tendência para hierarquização e para a teleologia. Ou seja, a limitação da capacidade emancipadora da inversão é a própria inversão enquanto manutenção dos limites.

21 A inversão que diferencia o modo como o museu se dá a ver na atualidade apresenta, todavia, algumas particularidades. É certo que o museu perde a sua posição central, autoritária e normativa, ao passo que o público é valorizado. Porém essa valorização decorre de um deslocamento ao nível da função do público - da passividade para a atividade - sem que os termos sejam questionados em si mesmos ou na sua disposição: o ativo mantem-se como termo maior que comanda a estrutura.

É esta ambivalência que sustenta a sacralidade do público nos museus de hoje. Tomando alguma liberdade para com a reflexão de Agamben acerca do homo sacer podemos aplicar ao visitante a fórmula dupla que menciona «a impunidade da sua morte e a interdição do sacrifício» (Agamben 1998, 75). Por um lado, o público deve perder os traços que o qualificavam como tal e que derivavam da sua passividade. Por outro lado, tornado ativo, ele passa a ocupar a posição central para a qual a instituição se orienta. Ao morrer como público passivo torna-se ativo e é-lhe atribuído, em grande parte, o dever de salvar a própria instituição trazendo a vida - a sua vida - para dentro desta.

Este duplo estatuto do público - remédio e veneno para retomamos os termos que caraterizam o pharmakon (Derrida 2005a) - constitui aquilo que Rancière qualificou como o paradoxo do espetador (Rancière 2010), o qual é considerado simultaneamente como indispensável e como parte maldita. A maldade do espetador situa-se na suposta passividade que o afasta da possibilidade de conhecer e de agir. A aposta dos reformadores será, então, a de constituir o espetador como «voyeur passivo» a fim de resgatá-lo como «participante ativo» (Rancière 2010, 10).

Para avaliarmos a ativação do público no museu de hoje será interessante reler a emancipação do espetador (Rancière 2010) e, junto a esta, o nascimento do leitor (Barthes 1988) e através dessa releitura recordar que a emancipação nunca compreende o estabelecimento de uma cena de passividade visando a sua posterior superação mediante o deslocamento do espetador para o centro do palco. Que a morte do autor não conduz à reivindicação dos direitos de paternidade do texto por parte do leitor. Que a textualidade como impossibilidade da origem em Roland Barthes e a igualdade de inteligências como ponto de partida em Jacques Rancière impedem que o reconhecimento do leitor/ espetador se reduza à sua transformação num autor-ator. Que, em suma, não podemos considerar de modo aproblemático a ativação do público, como se a passagem do passivo ao ativo fosse suficiente para gerar o nascimento do leitor e a emancipação do espetador. Ao invés, é preciso partir da iterabilidade do texto e da igualdade de inteligências para questionar a própria lógica de inversão. 
25 A inversão entre o pedagógico e o performativo - enquanto movimento de termos no interior de uma estrutura que se mantém (passivo/ativo) e de uma hierarquia que prevalece (valorização do ativo) - reduz as hipóteses de emancipação do público a uma recolocação deste na posição superior. Os indícios desse movimento são vários: a insistência no criador ativo de conteúdos; a mobilização de um conjunto de técnicas e de ambientes com vista à sua ativação; o enfoque numa personalização que atende a cada participante na «sua história, seus gostos, suas paixões» ${ }^{1}$ (Barthes 1988,66 ).

Levada às últimas consequências, a figura ideal de uma ativação máxima corresponde a uma voz autoral do público que - ao não ser capaz de romper com os «fantasmas do verbo feito carne e do espetador tornado ativo» (Rancière 2010, 35) - se aproxima de uma metafísica da participação.

A referência à metafísica poderá parecer contraditória quando a ativação coloca em causa a autoridade do museu como fonte única de um saber que se considerava imutável. Porém, é precisamente sobre este paradoxo que devemos refletir, pois a interrogação sobre quem fala será sempre incompleta se não questionarmos a própria fala.

A alusão a uma voz do público não alude aqui, obviamente, a uma dimensão fonética da participação, mas ao modo como a ativação evoca o fonocentrismo (Derrida 2005a). De acordo com Derrida, o pensamento ocidental valorizou historicamente a fala por considerar que esta implicava a presença do sujeito falante e uma ligação imediata entre este e o significado, ou seja, uma presença do querer dizer do sujeito no sentido. A escrita, permanecendo legível na ausência do sujeito, sempre foi considerada órfã, uma mera mediação representativa da fala, marcada por uma repetibilidade que continuamente deslocava o sentido.

Podemos encontrar vestígios desta hierarquização no modo como o modelo participativo é estabelecido, em grande parte, através da associação do museu de ontem a uma mediação e a uma ausência, ou seja, a uma escrita. Não só a narrativa do museu impor-se-ia ao público, interpondo-se entre este e o conhecimento que ele poderia construir, com o texto museológico existiria independentemente dos visitantes e mesmo na sua ausência.

Assim, a transição entre o museu de ontem e o museu de hoje é apresentada sob a forma de uma passagem da má escrita do museu para a voz do público mediante uma valorização, qualitativa e quantitativa, da presença dos visitantes e das relações imediatas que estes estabelecem no seio da experiência museológica.

31 Porém, como antes referimos, a própria ambivalência da inversão introduz um paradoxo na qualificação metafísica da participação. Na medida em que a voz do público se faz ouvir a partir do recuo da autoridade do museu tradicional como estabelecer agora uma fundamentação para o sentido? A possibilidade de atribuir um valor e de estabelecer uma economia do sentido deixa de depender de um referente material ou idealmente exterior, mediado pelo museu e passa a assentar diretamente na atividade de cada visitante. Ou seja, a atividade e o sentido tendem a coincidir.

Nesta medida a economia do sentido no museu atual aproxima-se da lógica do performativo (Austin 1990), a qual caracteriza os enunciados que não se limitam a descrever ou a constatar um facto, mas produzem ou realizam a própria ação a que se referem. J. L. Austin, ao refletir sobre como fazer coisas com palavras, afirmava que os performativos, não sendo nem verdadeiros nem falsos, são apenas bem ou mal sucedidos, felizes ou infelizes (Austin 1990, 29-37). A metafísica da participação parece indicar que a 
diferença e a atratividade do museu de hoje reside no facto deste ser, sempre, um museu feliz.

\section{Museu a mais: o complexo performativo}

Num artigo elaborado por três elementos do Institute For Learning Innovation (Estados Unidos) (Falk, Lynn e Dierking 2006) reencontramos a imagem de um museu feliz e atrativo, orientado para a performatividade do público e essencialmente diferente do museu normativo que no passado impunha monologicamente o seu poder perante a passividade dos visitantes. $O$ texto torna-se particularmente significativo na secção final intitulada Museums in the Twenty-First Century - onde são definidas as estratégias que permitirão ao museu adotar um new business model adaptado a uma economia do conhecimento em que o sucesso assenta na flexibilidade, na formação contínua e numa aprendizagem contextual. Os autores descrevem aqui um mundo de abundância no qual as necessidades básicas se encontram asseguradas e as relações entre lazer e trabalho se alteraram - «the problem (...) is not whether or not there will be food on the table, but what cuisine to eat» (Falk, Lynn, Dierking 2006, 335) - cabendo ao museu adaptar a sua oferta aos desejos individualizados dos visitantes, oferecendo experiências de lazer que possuam o valor acrescentado da aprendizagem e adotando uma abordagem qualitativa que reflita a sua capacidade de mudar vidas.

Será possível pensar o museu de hoje - um museu que se propõe captar e transformar a vida - apenas com base numa performatividade bem-sucedida, numa pura intencionalidade que se opõe e sucede à substancialização do poder na norma? Ou teremos que considerar uma outra relação entre o performativo e o normativo, uma relação onde a performance constitui a (im-)possibilidade da norma e a norma a (im-) possibilidade da performance?

Esta segunda hipótese obriga-nos, em primeiro lugar, a repensar o museu de ontem para lá da sua definição como centro autoritário de um poder imposto coercivamente a um público passivo. Parece ser esse o caminho seguido por Tony Bennett quando relata o nascimento do museu inscrevendo-o num processo mais amplo que designa de exhibitionary complex (Bennett 2005). Bennett reinterpreta a passagem, desenvolvida por Foucault, de um poder soberano exemplar e exibicionista para um poder disciplinar, confinante e corretivo, propondo um nó teórico entre o disciplinar e o espetacular, através de uma tecnologia da visão que articula o poder e o saber, o ver e o ser visto, a ordem das coisas e a ordem das pessoas. 0 exhibitionary complex implica uma disciplina expositiva, ou seja, um espaço de representação do poder que permite a visualização dos saberes disciplinares mediante uma retórica de progresso e uma visão classificadora e totalizadora. Estabelece-se deste modo uma ordem para os objetos (que engloba as coisas, mas também os outros, os "primitivos") e uma ordem para os sujeitos em relação aos objetos, enquanto membros da nação, atores e beneficiários do progresso.

Os visitantes não se limitam, porém, a observar o espectáculo, mas constituem o próprio espetáculo através de uma lógica do ver e do ser visto, de (auto)exibição e (auto)vigilância, que determina uma autorregulação por parte do público o qual, em última instância, interioriza o olhar do poder e acaba por partilhar a sua visão (do mundo). Deste modo, a norma corresponde a um determinado regime de verdade (Foucault 1998) que, combinando práticas discursivas e técnicas de poder, sustenta a 
performatividade e, simultaneamente, normaliza-a. Ao passo que a performance surge como desempenho de uma visão consensualizada do mundo, uma visão específica que se generalizou e tornou dominante sob a forma de hegemonia (Gramsci 1999).

Tony Bennett reinterpreta, portanto, o museu de ontem inscrevendo-o no exhibitionary complex e fá-lo, como dissemos, a partir de uma reescrita do pensamento de Foucault. 0 próprio Foucault, de certa forma, reescreve a sua obra em meados da década de $1970^{2}$ partindo da questão: o que somos hoje? (Foucault 2004). É talvez esta questão que importa aqui recolocar para possamos responder a uma outra: o que somos hoje no museu de hoje? Ou seja, a que corresponde, no museu atual, a performatividade inerente à metafísica da participação se não nos limitarmos a opô-la à normatividade e, paralelamente, o que poderá ser a atividade do público caso não circunscrevamos a sua análise a uma inversão entre o passivo e o ativo?

Estas perguntas introduzem aqui um desvio. Um desvio que nos conduz de Foucault à sociedade de controlo analisada por Deleuze (2008). Também Deleuze toma como ponto de partida a sociedade disciplinar, na qual predominava a figura do molde, da formatação confinada no espaço e no tempo, onde «não se parava de começar». Porém o disciplinar cedeu o seu lugar ao controlo: em vez do molde a modulação ilimitada, em variação permanente, disseminada no espaço e no tempo e onde "nunca se termina nada» (Deleuze 2008, 221).

Um dos modos desta modulação é, precisamente, a formação contínua entendida como formatação permanente na qual a edução deixa de estar confinada à escola e o controlo ao exame. Deleuze (2008) antevê aqui a empresarialização da aprendizagem no âmbito de um capitalismo que já não se dirige à concentração e à produção na fábrica, mas à dispersão com vista à competitividade, à competição do indivíduo divisível e à divida infinita do homem endividado.

Não recorremos aqui a Deleuze e à ideia de controlo com o objetivo de demonstrar a submissão do museu a uma lógica que lhe é exterior ou de desvendar uma agenda escondida sob o apelo à participação e à aprendizagem contínua. Trata-se antes de colocar a hipótese da atratividade do museu de hoje resultar menos de relações sociais ou cognitivas inovadoras do que da sua inscrição num modelo justificativo mais amplo, ou seja, num espírito do tempo que é o espírito do capitalismo.

41 Esta noção está presente em Boltanski e Chiapello (2009), para quem o capitalismo, na ausência de uma atratividade intrínseca, tem necessidade de criar valores (modelo justificativo) com o objetivo de garantir o envolvimento generalizado e assim produzir valor (acumulação contínua). Cada novo espírito desenvolve-se a partir das críticas surgidas na fase anterior, adaptando-se a elas a fim de renovar a expansão do próprio capitalismo. De acordo com os autores, no final da década de 1960, a par da tradicional crítica social (desigualdade, exploração), a crítica artística (massificação, estandardização), até então restrita a círculos intelectuais, tornou-se determinante. A absorção desta crítica resultou num terceiro espírito, no qual o modelo fordista foi substituído por um capitalismo em rede, baseado na criatividade, na adaptabilidade, na sucessão de projetos, na valorização de identidades flexíveis e numa atividade generalizada sob a forma de uma indiferenciação entre a vida profissional e não profissional.

42 Esta aproximação entre trabalho e não-trabalho ${ }^{3}$ corresponde ao que Lazzarato e Negri (2001, 25-41) designam por trabalho imaterial. Segundo estes autores, o próprio 
desenvolvimento industrial e tecnológico levou a que a produção deixasse de depender do modelo de organização ditado pelo capital - assente no tempo e na quantidade de trabalho despendidos e, portanto, numa diferença entre a força de trabalho e a pessoa do trabalhador - e passasse a basear-se no «desenvolvimento do indivíduo social» (Lazzarato e Negri 2001, 28). Com a consolidação deste processo ${ }^{4}$, nos anos de 1960 e 1970, a ação do sujeito produtivo na sociedade pós-industrial assumiu a forma de uma «atividade abstrata ligada à subjectividade» (Lazzarato e Negri 2001, 25), implicando um «tempo de vida global, na qual é quase impossível distinguir entre o tempo produtivo e o tempo de lazer» (Lazzarato e Negri 2001, 30).

O cruzamento destas análises deixa antever a possibilidade da injunção contemporânea a uma performatividade generalizada corresponder a uma modulação permanente do vivo através de uma articulação entre a biopolítica (onde a vida se torna a matéria sobre a qual o poder atua) e o capitalismo em rede (onde a reapropriação da crítica artística conduz à indistinção entre a produtividade e a vida). Estaremos, assim, perante uma situação bioestética onde a passagem da zôê - «o simples facto de viver comum a todos os seres vivos» - para o bios - a «maneira de viver própria de cada indivíduo ou grupo» (Agamben 1998, 11) - se efetiva através da estética ou de uma mediação estética entre o económico e o político.

Inscrito nesta perspectiva, o museu de hoje surge como um campo bioestético, no qual o desejo de captar a totalidade da vida deixou de se efetivar através da coleção e passou a concentrar-se no próprio público a quem cabe trazer a vida - a vida toda, ou seja, o contexto pessoal, sociocultural, ambiental de cada um - para o museu a fim de usufruir aí de uma experiência que, por sua vez, pretende ser única e mudar a totalidade da vida.

Nessa medida não é possível opor linearmente o museu de hoje ao de ontem. Pelo contrário, o museu atual situa-se num complexo performativo que pode ser entendido como uma ampliação do complexo exibicionista através de uma expansão da (auto)regulação para a (auto)produtividade.

Não se trata aqui, obviamente, de uma pedagogia ou de um adestramento específico dirigido à produção, onde se manteria a distinção entre o indivíduo e a sua atividade. Trata-se antes de um entendimento da participação enquanto performatividade e da performatividade enquanto produtividade geral. Ou seja, uma performatividade que gera mais produtividade e uma produtividade que gera mais performatividade. Uma produtividade da produtividade e uma produtividade de si sob o modo flexível do investimento e sob a forma contínua da modulação ${ }^{6}$.

É neste laço que une a performatividade à produtividade enlaçando o vivo que devemos procurar a resposta à pergunta sobre o modo de subjetivação em causa no museu atual e quais as suas relações com o saber e o poder, ou seja, sobre o que somos hoje no museu de hoje.

\section{Excipit}

É fundamental reiterar a importância de participar, de tomar parte de modo pleno. É necessário repetir que a participação constitui o princípio de uma política democrática nos museus tanto por permitir uma desnaturalização das hierarquias anteriores como pelo valor estratégico e prefigurativo que pode possuir ao nível do fortalecimento dos 
públicos. Mas é igualmente urgente reafirmar que essa relevância obriga a uma constante reflexão crítica sobre a prática teórica que a sustenta.

A análise que desenvolvemos conduziu-nos a uma estranha economia. O museu de hoje evoca a imagem do lar, do lugar onde o público deve sentir-se em casa, ao mesmo tempo que provoca o estranhamento familiar de algo que está sempre a menos ou a mais. Museu a menos, no qual a posição autoritária da pedagogia se esvaziou a favor de uma metafísica da participação enquanto voz autoral do público. Museu a mais onde a experiência museológica capta a totalidade da vida mediante uma conexão entre performatividade e produtividade.

50 Não nos parece, contudo, suficiente apontar um impasse entre o mais ou o menos sem simultaneamente refletir sobre a possibilidade de «alterar o cálculo» ${ }^{7}$ (Bhabha 1998, 219), de pensar o museu como um mais e um menos e, a partir daí, repensar a participação do público.

51 A metafísica da participação, enquanto intencionalidade, e o complexo performativo, enquanto produtividade, requerem que o museu seja o lugar feliz de uma performatividade bem-sucedida. Contudo, mesmo nas instituições mais abertas à participação, o museu mantém-se como enquadramento da atividade do público, moldura tornada invisível por uma transparência calculável. A participação, completa em si mesma, é assim amparada, aumentada, por esse enquadramento (Derrida 2005, 64-70), assumindo a forma de uma reiteração da norma participativa e de uma normalização da produtividade.

52 Alterar o cálculo implica, por isso, reconhecer a necessidade do fracasso do performativo (Derrida 1991, 362-370) e a estrutura citacional da experiência do e no museu. A partir daí será possível uma reflexão crítica sobre a arbitrariedade de uma convenção participativa que assenta numa consensualização dos objetivos da instituição e numa retórica de serviço (Lynch 2011a, Lynch 2011b). Ao mesmo tempo a im-completude da participação permitirá desenlaçar o laço que une a performatividade, a intencionalidade e a produtividade e repensar os modos de subjetivação e de circulação do sentido a partir de uma lógica de repetição e alteridade.

53 Assumir que a relação entre o museu e público assenta num processo de suplementaridade, para além de possibilitar uma reflexão crítica, poderá contribuir igualmente para a disseminação da escrita do museu por outros contextos e para o enxerto nessa escrita de elementos anteriormente situados nas suas margens, abrindo a possibilidade dessa relação ser, por sua vez, suplementada por um outro outros excluídos, no espaço e no tempo, da inclusividade do museu.

54 Tratar-se-á, em suma, de substituir a retórica do serviço e a a-política do consenso pelo dever da hospitalidade e do testemunho. Uma hospitalidade que não se fundamenta na casa, na propriedade, no museu - no museu como casa -, mas num acolhimento sem condições e sem cálculos (Derrida 2005c), através de uma im-propriedade comum - os comuns em vez da propriedade - sob a forma de uma guarda conjunta (Marstine 2011).

Um testemunho «no qual quem é sem palavra leva o falante a falar, e quem fala carrega em sua própria palavra a impossibilidade de falar» (Agamben 2008, 124), estabelecendo uma indecidibilidade entre a de-subjetivação e a subjetivação, o indizível e o dizível, o silêncio a vítima de um diferendo cujas regras de juízo tornam o dano irreparável (Lyotard 1983, 18-29) - e a voz dos sem voz - a parte dos sem parte que altera a distribuição do sensível (Rancière 2006). 
provável que assim esboçadas estas figuras - do suplemento, da hospitalidade e do testemunho - não tenham o rigor das notas finais, o bom rigor que finalizaria o texto. É possível que sejam apenas traços do museu de hoje como museu por vir. Mas talvez esta seja a única conclusão possível para um texto que apenas procurou demonstrar que o seu título é apropriado, um título ao portador.

\section{BIBLIOGRAFIA}

Agamben, Giorgio. 1998. Poder Soberano e a Vida Nua: Homo Sacer. Lisboa: Editorial Presença.

Agamben, Giorgio. 2008. O que Resta de Auschwitz: 0 Arquivo e a Testemunha. São Paulo: Boitempo.

Agamben, Giorgio. 2011. The Kingdon and the Glory: For a Theological Genealogy of Economy and Government (Homo Sacer II, 2). Stanford: Stanford University Press.

Austin, John Langshaw. 1990. Quando Dizer é Fazer. Porto Alegre: Artes Médicas.

Barthes, Roland. 1988. O Rumor da Língua. São Paulo: Editora Brasiliense.

Bennett, Tony. 2005. The Birth of the Museum. London, New York: Routledge.

Bhabha, Homi. 1998. “DissemiNação.” In O Local da Cultura, de Homi Bhabha, 198-238. Belo Horizonte: Editora UFMG.

Black, Graham. 2005. The Engaging Museum: An Interpretative Approach to Visitor Involvement. Abingdon, Oxon: Routledge.

Boltanski, Luc, e Ève Chiapello. 2009. O Novo Espírito do Capitalismo. São Paulo: Ed. Martins Fontes. Chakrabarty, Dipesh. 2002. "Museums in Late Democracies." Humanities Research IX (1): 5-12.

Dean, Jodi. 2003. “Why the Net is Not a Public Sphere." Constellations 10 (1): 95-112.

Deleuze, Gilles. 2008. Conversações. São Paulo: Editora 34.

Derrida, Jacques. 1973. Gramatologia. São Paulo: Ed. Prespectiva.

Derrida, Jacques. 1991. Margens da Filosofia. Campinas: Papirus.

Derrida, Jacques. 2001. Posições. Belo Horizonte: Autêntica.

Derrida, Jacques. 2005a. A Farmácia de Platão. São Paulo: Iluminuras.

Derrida, Jacques. 2005b. La Verdad en Pintura. Buenos Aires: Paidós.

Derrida, Jacques. 2005c. “The Principle of Hospitality.” In Paper Machine, 66-69. Stanford: Stanford University Press.

Falk, John H. 2009. Identity and the Museum Visitor Experience. Walnut Creek: Left Coast Press.

Falk, John H., Lynn D. Dierking, e Marianna Adams. 2006. "Living in a Learning Society: Museums and Free-choice Learning." In A Companion to Museum Studies, editado por Sharon Macdonald, 323-336. Malden: Blackwell Publishing. 
Foster, Hal. 2004. "The exhibition 'This is Tomorrow' in London..." In Art Since 1900: Modernism, A ntimodernism, Postmodernism, editado por Hal Foster, Rosalind Krauss, Yve-Alain Bois, e Benjamin H.D. Buchloh, 385-390. London: Thames \& Hudson.

Foucault, Michel. 1993. "Verdade e Subjetividade (Howison Lectures)." Revista de Comunicação e Linguagem 10: 203-223.

Foucault, Michel. 1995. “O Sujeito e o Poder.” In Michel Foucautl, uma Trajetória Filosófica, Hubert Dreifus, e Paul Rabinow. 231-249. Rio de Janeiro: Forense Universitária.

Foucault, Michel. 1998. Microfísica do Poder. Rio de Janeiro: Edições Graal.

Foucault, Michel. 2004. Ditos \& Escritos V. Ética, Sexualidade, Política. Rio de Janeiro: Forense Universitária.

Foucault, Michel. 2005. Em Defesa da Sociedade. São Paulo: Martins Fontes.

Foucault, Michel. 2010. Nascimento da Biopolítica. Lisboa: Edições 70.

Gramsci, Antonio. 1999. Cuadernos de la Cárcel - Tomo 5. Puebla: Benemérita Universidad Autónoma de Puebla.

Harvey, David. 2008. Condição Pós-Moderna. São Paulo: Edições Loyola.

Hein, George. 2002. Learning in the Museum. London: Routledge.

Hooper-Greenhill, Eilean. 2007. "Education, Postmodernity and the Museum" In Museum Revolutions: How Museums Change and are Changed, editado por Simon J. Kelly, Suzenne MacLeod, e Sheila Watson, 367-376. London: Routledge.

Lazzarato, Maurizio e Antonio Negri. 2001. Trabalho Imaterial: Formas de Vida e Produção de Subjetividade. Rio de Janeiro: Editora DP \& A.

Lynch, Bernadette. 2011a. Whose Cake is it Anyway? A Collaborative Investigation into Engagement and Participation in Twelve Museums and Galleries in the UK. London: The Paul Hamlyn Foundation.

Lynch, Bernadette. 2011b. "Custom-made Reflective Practice: Can Museums Realise their C apabilities in Helping others Realise theirs?” Museum Management and Curatorship 26 (5): 441-458.

Lyotard, Jean-François. 1983. Le Différend. Paris: Ed. Minuit.

Marstine, Janet. 2011. "The Contingent Nature of The New Museum Ethics.” In The Routledge Companion to Museum Ethics, 2-25. London: Routledge.

Oberhardt, Suzanne. 2000. "Frames Within Frames: The Pedagogy of the Art Museum as Cultural Artifact." Tese de doutoramento, The Pennsylvania State University.

Rancière, Jacques. 2006. “O Dissenso.” In A Crise da Razão, editado por Adauto Novaes, 367-382. São Paulo: Companhia das Letras.

Rancière, Jacques. 2010. O Espetador Emancipado. Lisboa: Orpheu Negro.

Rentschler, Ruth. 2007. "Museum Marketing: No Longer a Dirty Word” In Museum Marketing: Competing in the Global Marketplace, editado por Ruth Rentschler e Anne-Marie Hede, 12-19.

Oxford: Elsevier.

Simon, Nina. 2010. The Participatory Museum, Santa Cruz, CA: Museum 2.0.

Stonard, John-Paul. 2007. "Pop in the Age of Boom: Richard Hamilton's 'Just what is it that Makes Today's Homes so Different, so Appealing?"” Burlington Magazine CXLIX: 607-620. 


\section{NOTAS}

1. Roland Barthes carateriza com estes termos a autoridade do autor na cultura popular. Quanto ao leitor, Barthes define-o de modo bem distinto: «um homem sem história, sem biografia, sem psicologia» (Barthes 1988, 70).

2. Reescreve-a no duplo sentido em que esta pergunta irá orientar os seus trabalhos desses anos e oferecer uma outra chave de leitura para os escritos anteriores, destacando como fio condutor da sua reflexão não somente o poder ou o saber mas os «modos pelos quais (...) os seres humanos tornaram-se sujeitos» (Foucault 1995, 231), através das «relações entre verdade, poder e si mesmo» (Foucault 2004, 300). Daí a atenção crescente de Foucault às técnicas éticas de si, aos processos de subjetivação que se traduzem em práticas de si, ao modo produtivo como o sujeito estabelece a sua conduta, o seu modo de ser (Foucault, 1993).

3. Tanto John H. Falk como Nina Simon citam entusiasticamente Geoff Godbey, um professor de leisure studies, quando este afirma que «To be most satisfying, leisure should resemble the best aspects of work» (Falk 2009, 44, Simon 2010, 16-17).

4. Baseando-se no poder constituinte da intelectualidade de massa a avaliação de Lazzarato e Negri às possibilidades abertas pelo trabalho imaterial é, no geral, otimista. Resta saber em que medida este poder constituinte - a menos que se mantenha como indeterminação absoluta ou como potência de não - não será sempre recuperável sob a forma de uma produtividade generalizada geradora de novas sujeições do sujeito.

5. Foucault situa a politização da vida na passagem do "fazer morrer" próprio do poder soberano para o "fazer viver" inerente ao biopoder. A noção de biopolítica, embora centrada na administração da população, articula tópicos divergentes como a disciplina e a regulação, a individualização e a totalização, a subjetivação e a objetivação (Foucault 2005, 285-304). De igual modo não se circunscreve a uma governamentalidade específica. Pode desenvolver-se ao nível da Razão de Estado, através da polícia, onde se procura governar sempre mais com o objetivo de tornar a população o mais numerosa e ativa possível e assim fortalecer o Estado (Focault 2004). Ou pode surgir no âmbito do liberalismo, em que se considera que se governa sempre de mais e onde a atividade do governo é calculada com base na utilidade económica e na verificação pelo mercado. A "máxima economia" do governo ao nível do mercado e em nome da sociedade não impede, porém, uma ampliação da racionalidade concorrencial ao conjunto da vida ( Teoria do Capital Humano no neo-liberalismo americano), nem o surgimento do homo economicus que continuamente investe em si próprio numa lógica empresarial (Foucault 2010).

6. Neste âmbito importaria, obviamente, um estudo de pormenor que medisse as proximidades e pesasse as diferentes entre: a orientação para o público (Simon 2010) e a adequação pós-fordista da oferta à procura (Harvey 2008); a atenção à diversidade dos visitantes (Rentschler 2007) e as "alegrias do marketing» (Deleuze 2008, 224); a planificação holística (Black 2005, Hein 2002) e o princípio de «economia máxima» (Foucault 2010); a aprendizagem ampliada (Falk, Lynn e Dierking 2006) e a modulação contínua (Deleuze 2008); o recurso a novas tecnologias (Simon 2010) e o capitalismo comunicativo (Dean 2003). 
7. Usamos aqui uma expressão de Homi Bhabha no seu artigo sobre a escrita da nação enquanto disseminação. Explorando uma ambivalência entre o pedagógico e o performativo, Bhabha refere-se à reflexão de Derrida sobre a lógica do suplemento entendido como algo que simultaneamente «cumula e acumula a presença» e «cumula um vazio», dando conta «da falta anterior de uma presença» (Derrida 1973, 178).

\section{RESUMOS}

O presente artigo tem como objetivo afirmar a importância da participação do público na experiência museológica. Essa afirmação implica, contudo, que a participação não deve ser assumida como um facto previamente dado, mas requer uma reflexão crítica sobre as suas próprias bases. Num primeiro momento demonstraremos como o museu de hoje se apresenta a si mesmo como um lugar de atratividade, atividade e performatividade essencialmente diferente do museu autoritário e pedagógico do passado. Em seguida tentaremos complicar esta imagem através de um exercício interdisciplinar de co-implicação entre a narrativa do museu e as abordagens teóricas de outras áreas do conhecimento. Tal levar-nos-á a uma dupla leitura na qual o museu parece estar sempre marcado por uma falta ou por um excesso. Uma "falta" de museu onde uma metafísica da participação procura ligar intencionalidade e sentido através de uma lógica de ativação. Um "excesso" de museu onde uma performatividade sempre bemsucedida constitui o paradigma de uma situação contemporânea que podemos qualificar como bioestética. Contudo, esta dupla leitura não conduz necessariamente a um impasse. 0 reconhecimento da suplementaridade entre o museu e o público contém a possibilidade de desatarmos o nó que liga a participação à intencionalidade e à produtividade. Fazê-lo é abrir o texto museológico a elementos que habitualmente ficam nas suas margens e, assim, reforçar a própria ideia de participação.

The present article affirms the importance of participation in the museological experience. This affirmation implies, however, that participation should not be assumed as a pre-given fact, but requires a critical reflection on its own bases. Firstly, we will examine how today's museum presents itself as a place of attraction, activity and performativity, essentially different from the authoritarian and pedagogical museum of the past. Then, we will try to complicate this image through an interdisciplinary exercise of co-implication between the museum's narrative and some theoretical approaches from other areas of knowledge. This will lead us to a double reading where the museum seems to be always marked by something that is lacking or in excess. A "lack" of museum where a metaphysic of participation connects intentionality and meaning through logics of activation. An "excess" of museum where an ever successful performativity constitutes the paradigm of a contemporary situation that can be qualified as bio-aesthetic. However, this double reading doesn't necessarily mean an impasse. The recognition of the supplementary between museum and public embodies the possibility of untying participation from intentionality and productivity. To do so is to open the museum's text to elements forced to stay on its margins and to reinforce the very idea of participation. 


\section{ÍNDICE}

Keywords: museum, participation, biopolitics, public

Palavras-chave: museu, participação, biopolítica, público

\section{AUTOR}

\section{IVO ANDRÉ BRAZ}

Mestre em História de Arte Contemporânea pela Faculdade de Ciências Sociais e Humanas da Universidade Nova de Lisboa. Tem publicado diversos textos sobre arte contemporânea portuguesa, entre os quais Pensar a Pintura. Helena Almeida, 1967-1979 (ed. Colibri, 2007), «Sombra Projectada de KWY» (in KWY \& Nouveau Réalisme ed. Proteína, 2009), «Alguns Corpos - Regimes de Corporeidade e Estratégias de Representação na Arte Portuguesa (1879-1979)» (in Arte \& Erotismo ed. Instituto de História da Arte, 2012). Na área da curadoria co-comissariou, entre outras, as exposições The Last First Decade (Fundação Ellipse, 2011), Nadir Afonso: As Cidades no Homem (Assembleia da República, 2009), Turn Me On (Pavilhão 28, 2008). braz.ivo@gmail.com 